\title{
Dysplastic cerebellar gangliocytoma (Lhermite- Duclos disease): a rare entity and review of literature
}

Keywords: hamartoma, syndrome, incidence, thyroid, manifestation, signals, histopathology

\section{Introduction}

Cowden's syndrome, also called "multiple hamartoma-neoplasia syndrome", is an unusual autosomal dominant disorder characterized by mucocutaneous lesions, systemic hamartomas, and a high incidence of breast thyroid, genito-urinary, and endometrial cancers. Dysplastic cerebellar gangliocytoma is a major manifestation of Cowden syndrome and was first described by Lhermitte et al. ${ }^{1-3}$

\section{Case history}

A thirty three old male patient was referred to our institute with complaints of neck pain, headache and giddiness. He was evaluated and MRI brain done revealed a mixed signal lesion with T1W low signal and T2W/FFLAIR bright signals with a corduroy appearance of the left lobe of cerebellum along with compression of fourth ventricle and dilatation of third and fourth lateral ventricle. Complete removal of the lesion was done and sample was sent for histopathology.

\section{Discussion}

Lhermite-Duclos disease (LDD) is a distinct entity of the cerebellum by its unique pathological and radiological findings, and strong association with CS. The exact nature of this lesion is unclear, but it has been considered as a hypertrophy, a hamartoma, or a benign neoplasm. The terminologies mentioned previously include hamartoma of the cerebellum, hamartoblastoma, granule cell hypertrophy, diffuse ganglioneuroma of the cerebellar cortex, gangliocytoma myelinicum, myelinated neurocytoma, and Purkinjeoma. ${ }^{4}$ Most cases are reported in adults and PTEN mutations have been identified in virtually all cases of adult-onset disease. ${ }^{5}$ The most common clinical presentation is dysmetria. The other signs include signs and symptoms of mass effect including cranial nerve deficits and seizures. ${ }^{6} \mathrm{MRI}$ is a sensitive investigation which reveals enlarged folia with alternating T1hypointense and T-2 hyperintense tiger-striped striations, which do not enhance. ${ }^{7}$

The cerebellum displays hypertrophy with a coarse gyral pattern and is usually confined to one hemisphere. Microscopically diffuse enlargement of the molecular and internal granular layers of the cerebellum filled with ganglion cells of varying dimensions are noted. The architecture is preserved; the folia are enlarged but not obliterated. Scattered granule neurons are occasionally found in the molecular layer. Purkinje cells are reduced in number. Calcification and ectatic vessels are commonly noted. ${ }^{8}$ Immunohistochemistry reveals synaptophysin positivity in the dysplastic ganglion cells. PTEN protein expression is lost in most of the dysplastic cells, while increased expression of phosphorylated AKT and S6 are noted. Proliferative activity is very low. ${ }^{5,8}$ Antibodies like LEU4, PCP2, PCP4 and calbindin have been found to label few large atypical ganglion
Volume 6 Issue 2 - 2018

\author{
Partheeban Balasundaram,' Mallikarjuna VS,' \\ Suresh Bapu KR ${ }^{2}$ \\ 'Department of Histopathology, SRM Institute for Medical \\ Sciences, India \\ ${ }^{2}$ Department of Neurosurgery, SRM Institute for Medical \\ Sciences, India
}

Correspondence: Partheeban Balasundaram, Department of Histopathology, SRM Institute for Medical Sciences, Tamil Nadu 600026, India, Email drparthee@gmail.com

Received: December 09, 2017 | Published: March 13, 2018

cells, but not with the majority of neuronal elements indicating that the origin may be from the Purkinje cell source. The primary cell of origin suggested to be the cerebellar granule neuron. ${ }^{9}$ Patients with CS have high risk of breast and thyroid carcinomas, mucocutaneous lesions, gastrointestinal hamartomas, early onset uterine leiomyomas, macrocephaly and mental retardation, all of which are attributed to the germline mutation of PTEN gene. ${ }^{10}$

\section{Conclusion}

In LDD, no prognostic or predictive markers have emerged. It is still considered as a hamartamatous lesion/WHO grade I tumour. The important factor in CS is to have an adequate follow-up to look for malignancies of breast and thyroid gland, which is a manifestation of the disease.

\section{Acknowledgements}

None.

\section{Conflict of interest}

The author declared that there is none of the conflicts.

\section{References}

1. Nelen MR, Padberg GW, Peeters EA, et al. Localization of the gene for Cowden disease to chromosome 10q22-23. Nat Genet. 1996;13(1):114 116

2. Lhermitte J, Duclos P. Sur un ganglioneurome diffuse du coertex du cervelet. Bull Assoc Fr Etud Cancer. 1920;(9):99-107.

3. Spiegel E. Hyperplasie des Kleinhims. Beitr Pathol Anat. 1920;(67):539548.

4. Heilman CB, Shucart WA. Unusual neoplasms of the fourth ventricle. In: Cohen AR, editor. Surgical Disorders of the Fourth Ventricle, Cambridge: Blackwell Science; 1996. p. 262-271.

5. Zhou XP, Marsh DJ, Morrison CD, et al. Germline inactivation of PTEN and dysregulation of the phosphoinositol-3-kinase/Akt pathway 
cause human Lhermitte-Duclos disease in adults. Am J Hum Genet. 2003;73(5):1191-1198.

6. Vinchon M, Blond S, Lejeune JP, et al. Association of Lhermitte-Duclos and Cowden disease: report of a new case and review of literature. $J$ Neurol Neurosurg Psychiatry. 1994;57(6):699-704.

7. Wei G, Zhang W, Li Q, et al. Magnetic resonance characteristics of adult-onset Lhermitte-Duclos disease: An indicator for active cancer surveillance? Mol Clin Oncol. 2014;2(3):415-420.
8. Abel TW, Baker SJ, Fraser MM, et al. Lhermitte-Duclos disease: a report of 31 cases with Immunohistochemical analysis of the PTEN/AKT/ mTOR pathway. J Neuropathol Exp Neurol. 2005;64(4):341-349.

9. Hair LS, Symmans F, Powers JM, et al. Immunohistochemistry and proliferative activity in Lhermitte-Duclos disease. Acta Neuropathol. 1992;84(5):570-573.

10. Bosman Ft, Carneiro F, Hruban RH, et al. WHO classification of Tumours of the Digestive system. 4th ed. Lyon, International agency for Research on Cancer: IARC Press; 2010. 417 p. 